\title{
Open Circuit Fault Diagnosis Using Stator Resistance Variation for Permanent Magnet Synchronous Motor Drives
}

\author{
Byoung-Gun Park ${ }^{*}$, Rae-Young Kim ${ }^{* *}$, and Dong-Seok Hyun ${ }^{\dagger}$ \\ *Electric Propulsion Research Division, Korea Electrotechnology Research Institute (KERI), Changwon, Korea \\ ${ }^{* * \dagger}$ Department of Electrical and Biomedical Engineering, Hanyang University, Seoul, Korea
}

\begin{abstract}
This paper proposes a novel fault diagnosis scheme using parameter estimation of the stator resistance, especially in the case of the open-phase faults of PMSM drives. The stator resistance of PMSMs can be estimated by the recursive least square (RLS) algorithm in real time. Fault diagnosis is achieved by analyzing the estimated stator resistance of each phase according to the fault condition. The proposed fault diagnosis scheme is implemented without any extra devices. Moreover, the estimated parameter information can be used to improve the control performance. The feasibility of the proposed fault diagnosis scheme is verified by simulation and experimental results.
\end{abstract}

Key words: Fault diagnosis, Open switch fault, Parameter estimation, Permanent Magnet Synchronous Motor (PMSM)

\section{INTRODUCTION}

Permanent magnet synchronous motors (PMSM) have been widely used in various applications including electrical vehicles, appliances, aircraft, and industrial servo drives due to their high power density, precise controllability and large torque to inertia ratio. The reliability of PMSM drives is one of the critical factors in several industries. This is especially true in areas where precise operation and/or high performance are required. In these areas, a sudden drive failure may result in serious damages and economical losses [1], [2].

There are different types of faults that can occur in motor drives. The electrical faults in motor drives frequently occur in the motor and power electronic equipment connected to the motor. Faults in the motor result from stator faults which are defined by short or open-circuit faults of the stator windings, and rotor faults which include magnetic and electrical faults. Faults in power electronics equipment occur due to open or short-circuit faults in power devices and connection wires [3]-[5]. The reliability of motor drives can be improved with the development of fault diagnosis schemes for these faults.

In recent years, there have been many papers on fault

Manuscript received Jul. 11, 2012; revised Sep. 16, 2013

Recommended for publication by Associate Editor Sanjib K. Panda.

${ }^{\dagger}$ Corresponding Author: dshyun@hanyang.ac.kr

Tel: +82-2-2220-0345, Fax: +82-2-2220-0532, Hanyang University

*Electric Propulsion Research Division, Korea Electrotechnology Research Institute (KERI), Korea

${ }^{* * \dagger}$ Department of Electrical and Biomedical Engineering, Hanyang University, Seoul, Korea diagnosis of open-circuit faults [6]-[13]. Park's vector method [6] and the normalized DC current method [7]-[9] are accomplished by calculating the position of the current trajectory's midpoint, which is the mean value of the ac current space vector over one period. The phase voltage comparison method [10] and the lower switch voltage method [11] use measurement of the voltages to quickly diagnose open-circuit faults to reduce the amount of time between fault occurrence and diagnosis. However, these methods require additional voltage sensors to measure the phase voltages. The wavelet-fuzzy algorithm [12] and the wavelet-neural network method [13] use wavelet analysis to detect fault signatures. The wavelet transform is an emerging DSP algorithm that has variable time and frequency resolutions. However, these expert systems require a relatively high computing process. Most of the existing fault detection and identification methods have problems because the fault detection takes at least one fundamental period, the process for detecting faults is complex, and the schemes to identify faults are inadequate. Moreover, these methods use additional sensor for fault diagnosis.

This paper proposes a novel fault diagnosis scheme that is presented by a combination of the stator resistance variation's approach and the recursive least square (RLS) algorithm, especially in the case of the open faults of PMSM drives. The stator resistances of the PMSM are estimated by the RLS algorithm in real time. If an open-phase fault occurs, the stator resistance of the faulty phase estimated by the RLS algorithm is rapidly changed. This characteristic of stator resistance offers a simple algorithm for detecting open-phase faults. 


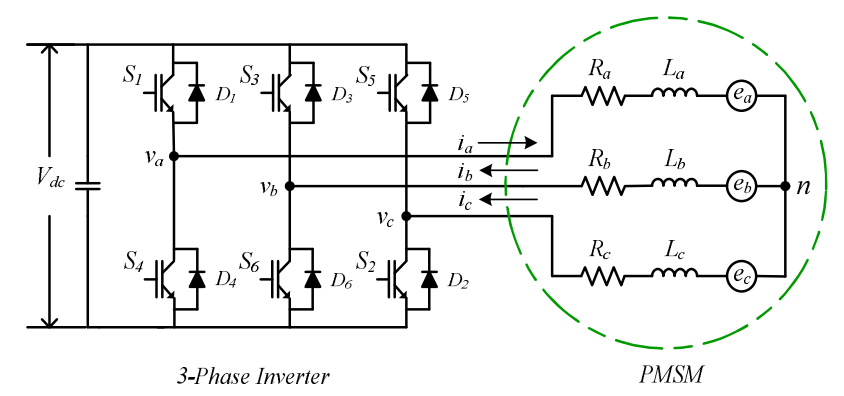

Fig. 1. The electrical equivalent circuit of PMSM drives.

The proposed fault diagnosis scheme can be implemented without any additional devices. Moreover, since it uses a simple algorithm, which only analyses the estimated stator resistances of each phase, the detection speed is very fast. The feasibility of the proposed fault diagnosis scheme is verified by several simulation and experimental results.

\section{MODELLING OF THE PMSM}

Generally, a PMSM drive system can be modelled as an electrical equivalent circuit that consists of a resistance, an inductance, and the back-EMF per phase. The electrical equivalent circuit for PMSM drives is shown in Fig. 1. Although the conventional d-q motor model obtained through the transformation of the phase voltage model is widely used to analyze and control AC motors, it cannot be used under open faults in switching devices. This is due to the fact that the 3-phase balanced condition no longer holds under an open fault and it is not easy to obtain the motor input voltage in the open phase from the pole-voltage.

Therefore, in the normal condition without faults, the dynamic model of a 3-phase balanced PMSM is written as:

$$
\left[\begin{array}{l}
v_{a} \\
v_{b} \\
v_{c}
\end{array}\right]=\left[\begin{array}{ccc}
R_{a} & 0 & 0 \\
0 & R_{b} & 0 \\
0 & 0 & R_{c}
\end{array}\right]\left[\begin{array}{l}
i_{a} \\
i_{b} \\
i_{c}
\end{array}\right]+\frac{d}{d t}\left[\begin{array}{ccc}
L_{a} & 0 & 0 \\
0 & L_{b} & 0 \\
0 & 0 & L_{c}
\end{array}\right]\left[\begin{array}{c}
i_{a} \\
i_{b} \\
i_{c}
\end{array}\right]+\left[\begin{array}{l}
e_{a} \\
e_{b} \\
e_{c}
\end{array}\right]
$$

where, $i_{a}, i_{b}$, and $i_{c}$ are the phases currents. $v_{a}, v_{b}$, and $v_{c}$ are the three-phase terminal voltages. $e_{a}, e_{b}$, and $e_{c}$ are the phase back-EMFs. $R$ and $L$ are the resistance and inductance of the phase windings.

The phase back-EMFs $\left(e_{a}, e_{b}\right.$, and $\left.e_{c}\right)$ can be approximately expressed as;

$$
\begin{aligned}
& e_{a}=\omega_{e} \lambda_{f} \cos \theta_{e} \\
& e_{b}=\omega_{e} \lambda_{f} \cos \left(\theta_{e}-2 \pi / 3\right) \\
& e_{c}=\omega_{e} \lambda_{f} \cos \left(\theta_{e}+2 \pi / 3\right)
\end{aligned}
$$

where $\lambda_{f}, \omega_{e}$, and $\theta_{e}$ represent flux linkage of the permanent magnet, electrical rotor speed, and electrical rotor position.
Equation (3) is derived by (1). This mathematical equation of a PMSM model is applied to the RLS algorithm.

$$
\frac{d}{d t}\left[\begin{array}{c}
i_{a} \\
i_{b} \\
i_{c}
\end{array}\right]=\left[\begin{array}{ccc}
-\frac{R_{a}}{L_{a}} & 0 & 0 \\
0 & -\frac{R_{b}}{L_{b}} & 0 \\
0 & 0 & -\frac{R_{c}}{L_{c}}
\end{array}\right]\left[\begin{array}{c}
i_{a} \\
i_{b} \\
i_{c}
\end{array}\right]+\left[\begin{array}{c}
\frac{1}{L_{a}} \\
\frac{1}{L_{b}} \\
\frac{1}{L_{c}}
\end{array}\right]\left[\begin{array}{l}
v_{a}-e_{a} \\
v_{b}-e_{b} \\
v_{c}-e_{c}
\end{array}\right]
$$

\section{RECURSIVE LEAST SQUARE ALGORITHM}

The recursive least squares (RLS) algorithm has mainly been used to estimate the parameters of motors due to its simple implementation. The general RLS algorithm is formulated as follows [14]:

$$
\begin{gathered}
Y(k)=\hat{\Theta}^{T} Z(k) \\
\hat{\Theta}(k)=\hat{\Theta}(k-1)+K(k)\left(\mathrm{Y}(k)-Z^{\mathrm{T}}(k) \hat{\Theta}(k-1)\right) \\
K(k)=\frac{P(k-1) Z(k)}{\lambda+Z^{T}(k) P(k-1) Z(k)} \\
P(k)=\frac{1}{\lambda}\left(P(k-1)-\frac{P(k-1) Z(k) Z^{T}(k) P(k-1)}{\lambda+Z^{T}(k) P(k-1) Z(k)}\right)
\end{gathered}
$$

where, $Y(k)$ is the output, $\Theta$ is the parameter vector, and $\hat{\Theta}$ is the estimated parameter vector $(\wedge$ denotes an estimated value). $Z(\mathrm{k})$ is the signal vector, $P(\mathrm{k})$ is the covariance matrix, and $\lambda$ is the forgetting factor given by $0<\lambda<1$. The forgetting factor is related to the sensitivity of the parameter variations.

For digital implementation of the RLS algorithm, the discrete dynamic model is required. The discrete phase current equation is given by:

$i_{a}(k)=\frac{L}{L+R \cdot T_{\text {samp }}} \cdot i_{a}(k-1)+\frac{T_{\text {samp }}}{L+R \cdot T_{\text {samp }}} \cdot\left(v(k)-e_{a}(k)\right)$

where, $T_{\text {samp }}$ is the sampling period.

The discrete time model in (8) is converted in (9), which is the discrete model for the application of the RLS algorithm.

$$
i_{a}(k)=a(k) \cdot i_{a}(k-1)+b(k) \cdot\left(v_{a}(k)-e_{a}(k)\right)
$$

From (9), the formulation of the RLS algorithm is obtained by;

$$
\begin{gathered}
\mathrm{Y}(k)=i_{a}(k) \\
\mathrm{Z}(k)=\left[\begin{array}{ll}
i_{a}(k-1) & v_{a}(k)-e_{a}(k)
\end{array}\right]^{T} \\
\hat{\Theta}(k)=\left[\begin{array}{ll}
a(k) & b(k)
\end{array}\right]^{T}
\end{gathered}
$$

The relation between the recursive equation coefficients and the motor parameters can be expressed as follows: 


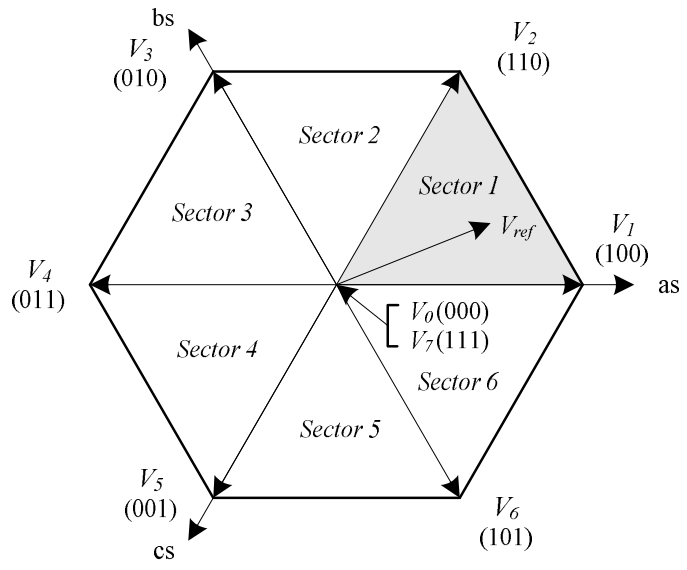

Fig. 2. Space vector modulation.
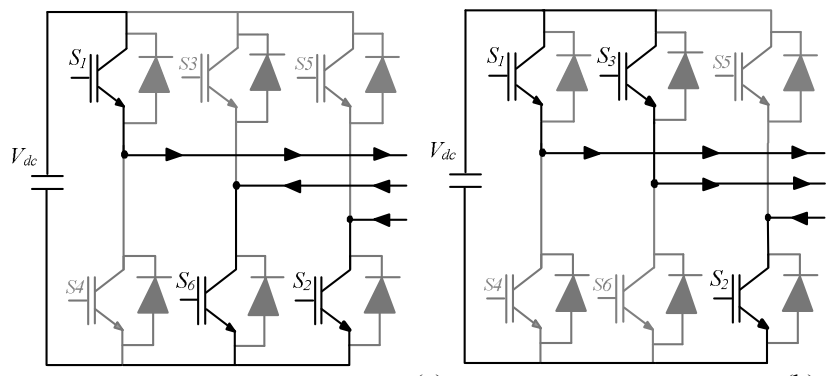

(a)

Fig. 3. Effective voltage vector (a) $V_{l}(100)$ (b) $V_{2}(110)$.

$$
\begin{aligned}
a(k) & =\frac{L_{a}(k)}{L_{a}(k)+R_{a}(k) \cdot T_{\text {samp }}}, \quad b(k)=\frac{T_{\text {samp }}}{L_{a}(k)+R_{a}(k) \cdot T_{\text {samp }}} \\
L_{a}(k) & =\frac{a(k) \cdot R_{a}(k) \cdot T_{\text {samp }}}{1-a(k)}=\frac{T_{\text {samp }}-b(k) \cdot R_{a}(k) \cdot T_{\text {samp }}}{b(k)} \\
\therefore & R_{a}(k)=\frac{1-a(k)}{b(k)}, \quad L_{a}(k)=\frac{a(k) \cdot T_{\text {samp }}}{b(k)}
\end{aligned}
$$

\section{PROPOSED FAUlt Diagnosis SCHEME}

As shown in Fig. 2, the operation region of the PMSM drive system is divided into the six triangular domains, denoted from Sector 1 to Sector 6, in the space vector pulse width modulation (SVPWM) hexagon.

\section{A. Fault Detection}

Generally the stator resistance of a PMSM is changed by variations in the temperature. Temperature variations can cause significant variations in the stator resistance. However, the stator resistance under general operation is determined by the temperature dependence, which is given by:

$$
R=R_{0} \cdot(1+\alpha \Delta T)
$$

where $R_{0}$ is the resistance at the reference temperature $T=25^{\circ} \mathrm{C}$, $\alpha$ is the resistance temperature coefficient, and $\Delta T$ is the temperature increase.

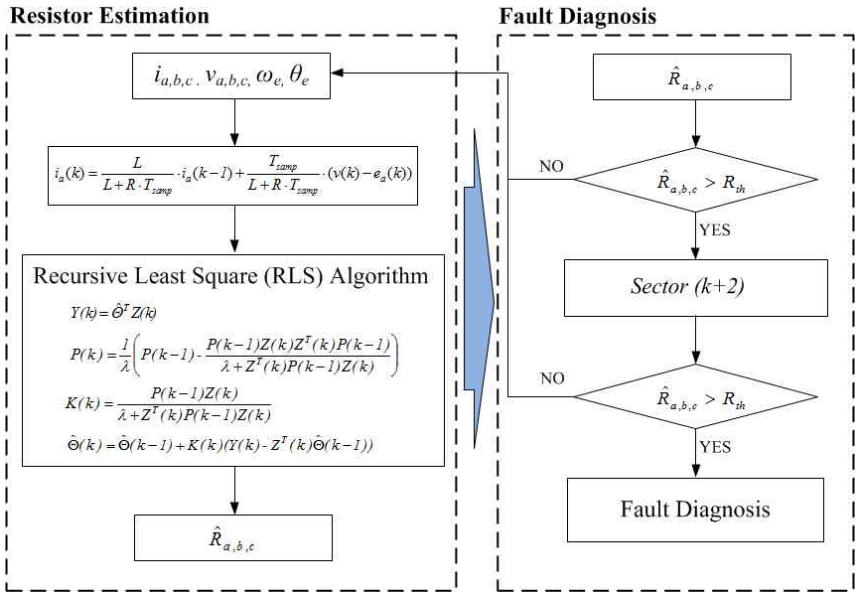

Fig. 4. Fault diagnosis flowcharts using $\bar{R} L S$ algorithm.

The timing flowchart of the proposed fault detection/ identification scheme is illustrated in Fig. 3, where the stator resistances of the PMSM are estimated by the RLS algorithm in real time. If an open-phase fault occurs, the stator resistance of the faulty phase estimated by the RLS algorithm is rapidly changed. The stator resistance varied by temperature can be clearly distinguished from that of an open-phase fault by its change rate. Therefore, the threshold value for detecting an open-phase fault must be larger than the variation of the stator resistance for the temperature effect. The algorithm for the fault detection is given by:

$$
\left\{\begin{array}{ll}
F_{D}=1 & \text { if } R_{t h}<\hat{R}_{a, b, c} \\
F_{D}=0 & \text { if } R_{t h}>\hat{R}_{a, b, c}
\end{array} \text { at } \operatorname{Sector}(k)\right.
$$

where, $R_{t h}$ is the threshold value of the stator resistance to continuously detect open-phase faults.

If the stator resistance $\left(R_{j_{-} R L S}\right)$ continuously estimated by the RLS algorithm is larger than the threshold value $\left(R_{t h}\right)$, the fault detection signal $\left(F_{D}\right)$ changes from low to high.

\section{B. Fault Identification}

After detection, it is possible to identify the position of a faulty phase in a minimum of two sectors. Similar phenomena are observed in the other sectors shown in Fig. 2. The identification of an open-phase fault is obtained by the fault identification signal $\left(F_{I}\right)$ when Sector $(k)$ is converted to Sector $(k+2)$. The algorithm for fault identification is given by:

$$
\left\{\begin{array}{ll}
F_{I}=1 & \text { if } R_{t h}<\hat{R}_{a, b, c} \\
F_{I}=0 & \text { if } R_{t h}>\hat{R}_{a, b, c}
\end{array} \text { at } \operatorname{Sector}(k+2)\right.
$$

The fault diagnosis is achieved by the fault signal $\left(F_{D}, F_{I}\right)$ at Sector $(k+2)$. For example, assuming that switch $S_{I}$ in Fig. 1 occurs in an open condition and the PMSM operates in Sector 1 shown in Fig. 3, the two effective vectors of $V_{I}(100)$ and 
TABLE I

RESISTANCE VARIATION FOR SECTOR 1-6

\begin{tabular}{|c|c|c|c|c|c|c|}
\hline & $\begin{array}{c}V_{l} \\
(100)\end{array}$ & $\begin{array}{c}V_{2} \\
(110)\end{array}$ & $\begin{array}{c}V_{3} \\
(010)\end{array}$ & $\begin{array}{c}V_{4} \\
(011)\end{array}$ & $\begin{array}{c}V_{5} \\
(001)\end{array}$ & $\begin{array}{c}V_{6} \\
(101)\end{array}$ \\
\hline$S_{l}$ & $\begin{array}{l}\mathrm{Ra} \uparrow \\
\mathrm{Rb} \uparrow \\
\mathrm{Rc} \uparrow\end{array}$ & $\begin{array}{l}\mathrm{Ra} \uparrow \\
\mathrm{Rb} \downarrow \\
\mathrm{Rc}-\end{array}$ & $\bullet$ & $\bullet$ & $\bullet$ & $\begin{array}{l}\mathrm{Ra} \uparrow \\
\mathrm{Rb}- \\
\mathrm{Rc} \downarrow\end{array}$ \\
\hline$S_{3}$ & $\bullet$ & $\begin{array}{l}\mathrm{Ra} \downarrow \\
\mathrm{Rb} \uparrow \\
\mathrm{Rc}-\end{array}$ & $\begin{array}{l}\mathrm{Ra} \uparrow \\
\mathrm{Rb} \uparrow \\
\mathrm{Rc} \uparrow\end{array}$ & $\begin{array}{l}\mathrm{Ra}- \\
\mathrm{Rb} \uparrow \\
\mathrm{Rc} \downarrow\end{array}$ & • & $\bullet$ \\
\hline$S_{5}$ & $\bullet$ & $\bullet$ & $\bullet$ & $\begin{array}{l}\mathrm{Ra}- \\
\mathrm{Rb} \downarrow \\
\mathrm{Rc} \uparrow\end{array}$ & $\begin{array}{l}\mathrm{Ra} \uparrow \\
\mathrm{Rb} \uparrow \\
\mathrm{Rc} \uparrow\end{array}$ & $\begin{array}{l}\mathrm{Ra} \downarrow \\
\mathrm{Rb}- \\
\mathrm{Rc} \uparrow\end{array}$ \\
\hline$S_{4}$ & $\bullet$ & $\bullet$ & $\begin{array}{l}\mathrm{Ra} \uparrow \\
\mathrm{Rb}- \\
\mathrm{Rc} \downarrow\end{array}$ & $\begin{array}{l}\mathrm{Ra} \uparrow \\
\mathrm{Rb} \uparrow \\
\mathrm{Rc} \uparrow\end{array}$ & $\begin{array}{l}\mathrm{Ra} \uparrow \\
\mathrm{Rb} \downarrow \\
\mathrm{Rc}-\end{array}$ & $\bullet$ \\
\hline$S_{6}$ & $\begin{array}{l}\mathrm{Ra}- \\
\mathrm{Rb} \uparrow \\
\mathrm{Rc} \downarrow\end{array}$ & $\bullet$ & $\bullet$ & $\bullet$ & $\begin{array}{l}\mathrm{Ra} \downarrow \\
\mathrm{Rb} \uparrow \\
\mathrm{Rc}-\end{array}$ & $\begin{array}{l}\mathrm{Ra} \uparrow \\
\mathrm{Rb} \uparrow \\
\mathrm{Rc} \uparrow\end{array}$ \\
\hline$S_{2}$ & $\begin{array}{l}\mathrm{Ra}- \\
\mathrm{Rb} \downarrow \\
\mathrm{Rc} \uparrow\end{array}$ & $\begin{array}{l}\mathrm{Ra} \uparrow \\
\mathrm{Rb} \uparrow \\
\mathrm{Rc} \uparrow\end{array}$ & $\begin{array}{l}\mathrm{Ra} \downarrow \\
\mathrm{Rb}- \\
\mathrm{Rc} \uparrow\end{array}$ & $\bullet$ & $\bullet$ & • \\
\hline
\end{tabular}

- no effect - no change

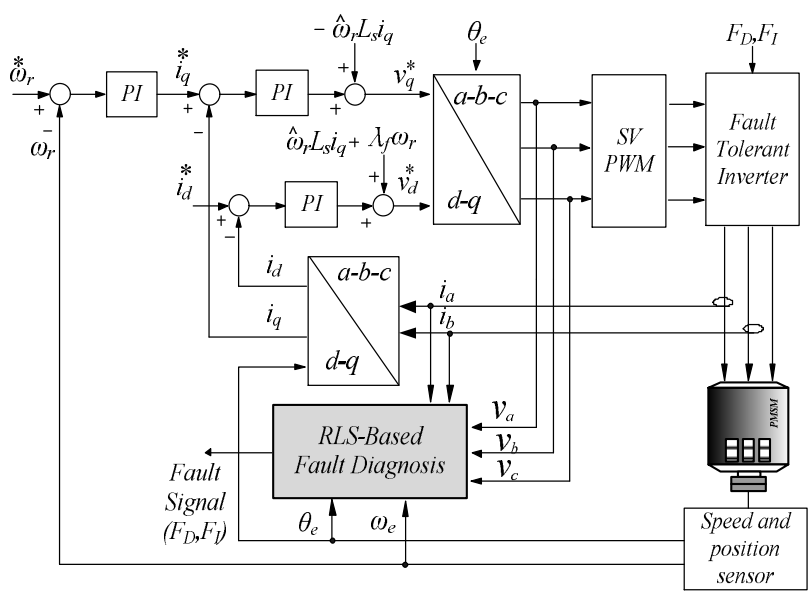

Fig. 5. Block diagram of the proposed RLS-based fault diagnosis.

$V_{2}(110)$ are generated from the inverter output. Consider the switch configurations under the $V_{I}(100)$ and $V_{2}(110)$ vectors, illustrated in the Fig. 3. Before an open fault of switch $S_{l}$, $V_{l}(100)$ is configured so that phase $\mathrm{A}$ is connected to the positive bus, and phase $\mathrm{B}$ and phase $\mathrm{C}$ are tied to the negative bus. $V_{2}(110)$ is configured with phase $\mathrm{A}$ and phase $\mathrm{B}$ connected to the positive bus, and phase $\mathrm{C}$ tied to the negative bus. However, after an open fault $V_{l}(100)$ has zero currents in each phase. Accordingly, all of the stator resistances of each phase increase. For $V_{2}(110)$, the current on phase A becomes zero, and phase $\mathrm{B}$ and phase $\mathrm{C}$ increase slightly to compensate the $\mathrm{q}$-axis current reduced by the faulty phase as compared to general operation.

Consequently, an open fault of $S_{I}$ at Sector 1 can be detected by observing the variation of the stator resistances, such as (i) the estimated stator resistance $R_{a}$ (of phase A) continuously increases for both $V_{l}(100)$ and $V_{2}(110)$, (ii) the estimated stator resistance $R_{b \_R L S}$ (of phase B) increases for

$V_{l}(100)$, but decrease for $V_{2}(110)$, and (iii) the resistance $R_{C_{-} R L S}$ (of phase C) increases for $V_{l}(100)$, and remain without any variation during $V_{2}(110)$. By applying this principle, the variation characteristics of the stator resistance to detect an open-phase fault is analysed in Sector 1-6.

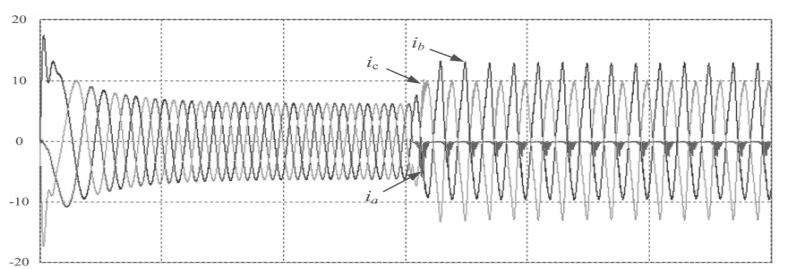

(a)

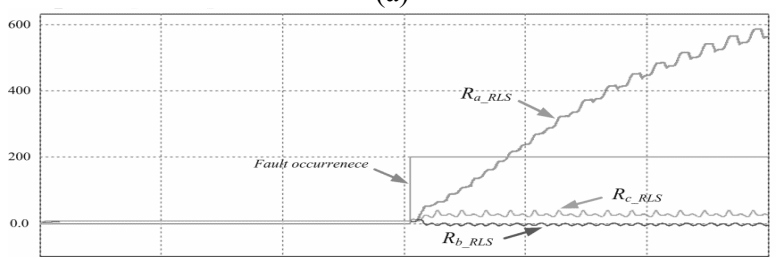

(b)

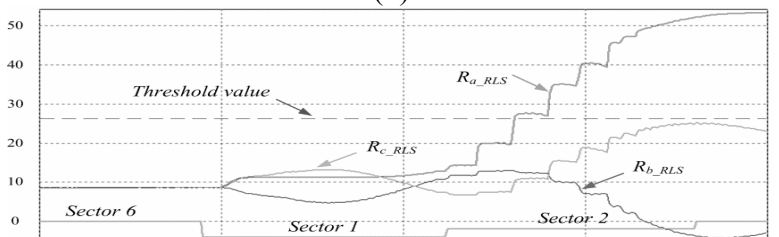

(c)

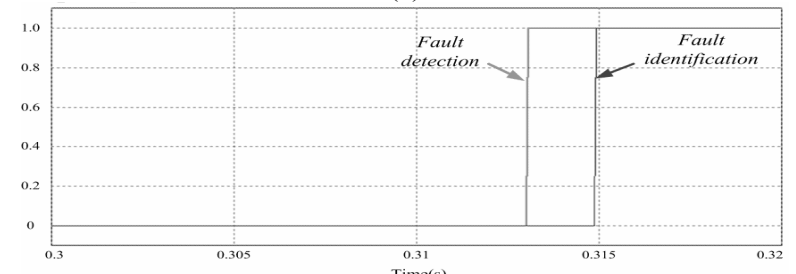

(d)

Fig. 6. Simulation results when switch $\mathrm{S}_{1}$ fault occurs. (a) Current waveform [A] (b) Estimated stator resistances $[\Omega]$ (c) Extended stator resistances $[\Omega]$ (d) Fault detection and identification signals.

TABLE I shows how the fault diagnosis algorithm under an open-phase fault is achieved in Sector 1-6 and the stator resistance change for the relationship between the switching states of Sector1-6. A block diagram for the overall structure of the proposed fault diagnosis system is shown in Fig. 5.

\section{SIMULATION AND EXPERIMENTAL RESULTS}

In order to verify the proposed fault diagnosis algorithm, simulations and experiments were performed under the same conditions. Fig. 6(a)-(d) show the simulation results of the proposed method by the RLS algorithm when an open-phase fault of switch $S_{1}$ occurs. The open-phase fault of phase A occurs at 0.394 [s]. Fig. 6(a) shows the current waveform under an open fault of switch $S_{I}$. The current of phase A becomes zero within about $11[\mathrm{~ms}]$ due to the open fault of phase A. As shown in Fig. 6(b) and (c), the stator resistance estimated by the RLS algorithm for the fault of phase A suddenly increase. After the fault of switch $S_{l}$, the stator resistances for each phase appear differently. Because of the open fault of switch $S_{l}$, the stator resistance of phase $\mathrm{A}$ in comparison with the other 


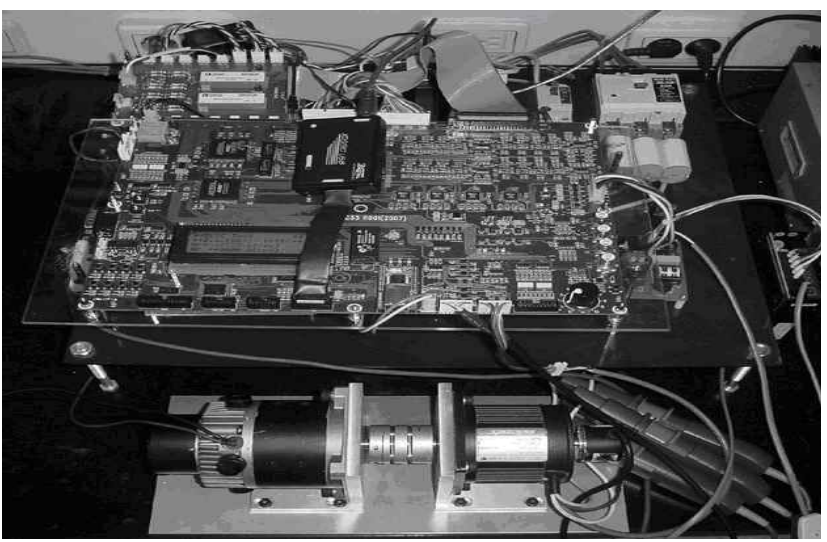

Fig. 7. Experimental setup for the proposed fault diagnosis.

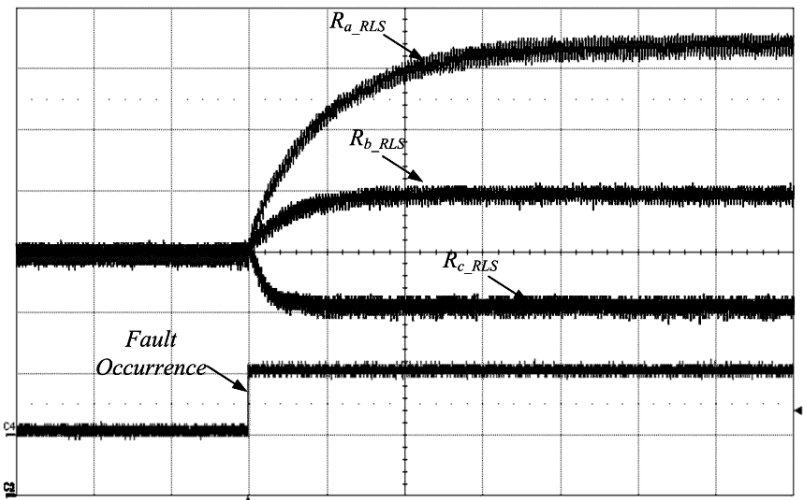

(a)

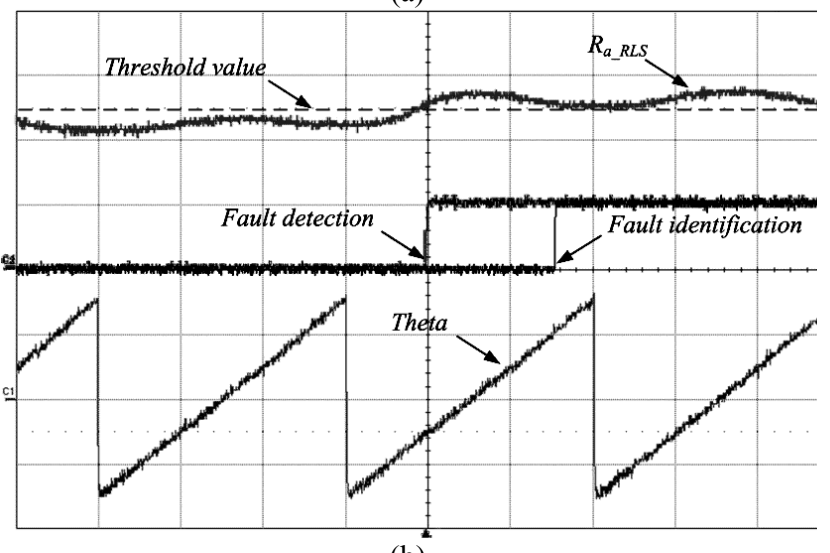

(b)

Fig. 8. Experimental results when switch $\mathrm{S}_{1}$ fault occurs. (a) Estimated stator resistances[ $\Omega]$ and fault signal. (b) $R_{a}$ RLS, Fault detection signal, Fault identification signal and Theta.

stator resistances increases rapidly. Fig. 6(d) shows the fault detection signal of phase A at $395.8[\mathrm{~ms}]$. In the simulation results, the fault detection signal is achieved by applying a threshold value that is set to $200 \%$ of the nominal stator resistance.

A laboratory prototype designed and built for the experiment is shown in Fig. 7. The main controller was configured by using a TMS320VC33 DSP where the sampling time in the control algorithm was $100 \mu \mathrm{s}$. The inverter used in the experiment was implemented with IPM PM20CJ060

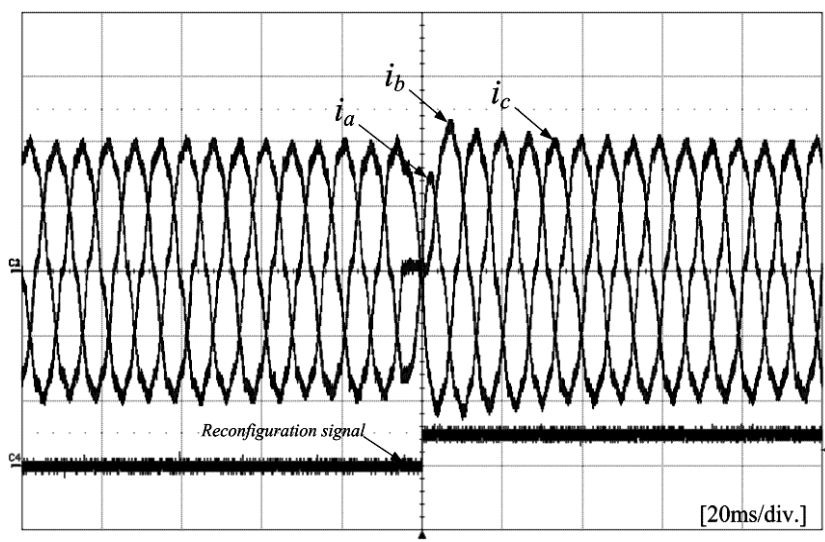

Fig. 9. Experimental results for reconfiguration after fault detection.

devices. A 250 W PMSM was coupled with laboratory prototype in order to test the proposed fault diagnosis algorithm.

In this paper, an open-circuit fault of switch $\left(S_{I}\right)$ was described by the enforced off-signal of the gate drive at the fault occurrence. Fig. 8(a) shows the experimental results for the estimated stator resistances $R_{a_{-} R L S}, R_{b_{-} R L S}$ and $R_{c_{-} R L S}$ and the fault signal in the switch $S_{l}$ fault. After the fault occurrence, $R_{a_{-} R L S}$ of the fault phase suddenly increases. If the stator resistance value $R_{a_{-} R L S}$ is larger than the given threshold value (th), the fault detection signal occurs and then the fault identification signal takes place within two sector, about $7[\mathrm{~ms}]$, as shown in Fig. 8(b).

Fig. 9 shows the current waveforms for three phases under fault tolerant control. Under an open fault of switch $S_{l}$, the current of phase A is decreased to zero at the positive period. After fault identification, the fault reconfiguration was achieved by the fault tolerant control. Then the three phase currents can flow through the motor.

\section{CONCLUSION}

In this paper, fault diagnosis using the RLS algorithm has been proposed to detect open-phase faults of the inverter switches in PMSM drives. The proposed scheme has been achieved by using the variation of the stator resistances, which are estimated by the RLS algorithm in real time.

The proposed fault diagnosis scheme can be implemented without any extra devices. Moreover, since it uses a simple algorithm using only the estimated stator resistances of each phase, it has a fast fault detection time. The feasibility of the proposed fault diagnosis scheme has been verified by simulation and experimental results.

\section{REFERENCE}

[1] B. M. Ebrahimi, J. Faiz, and M. J. Roshtkhari, "Static-, dynamic-, and mixed-eccentricity fault diagnoses in permanent-magnet synchronous motor, "IEEE Trans. Ind. Electron., Vol. 56, No. 11, pp. 4727-4739, Nov. 2009. 
[2] Y.-J. Ko and K.-B. Lee, "Fault diagnosis of a voltage-fed PWM inverter for a three-parallel power conversion system in a wind turbine," Journal of Power Electronics, Vol. 10, No. 6, pp.686-693, Nov. 2010.

[3] S. Bolognani, M. Ziglitto, and M. Zordan, "Innovative remedial strategies for inverter faults in IPM synchronous motor drives," IEEE Trans. Energy Convers., Vol. 18, No. 2, pp. 306-312, Jun. 2003.

[4] B.-W. Kim, K.-T. Kim, and J. Hur, "Simplified imped- ance modeling and analysis for inter-turn fault of IPM-type BLDC motor," Journal of Power Electronics, Vol. 12, No. 1, pp.10-18, Jan. 2012.

[5] W. le Roux, R. G. Harley, and T. G. Habetler, "Detecting rotor faults in low power permanent magnet synchronous machines," IEEE Trans. Power Electron., Vol. 22, No. 1, pp. 332-328, Jan. 2007.

[6] R. Peuget, S. Courtine, and J. P. Rognon, "Fault detection and isolation on a PWM inverter by knowledge-based model," IEEE Trans. Ind. Applicat., Vol. 34, No. 6, pp. 1318-1326, Nov./Dec. 1998.

[7] S. M. Cruz and A. Cardoso, "Stator fault diagnosis in three-phase synchronous and asynchronous motors," IEEE Trans. Ind. Applicat., Vol. 37, No. 5, pp. 1227-1233, Sep. 2001.

[8] W.-S. Im, J.-S. Kim, J.-M. Kim, D.-C. Lee, and K.-B. Lee, "Diagnosis methods for IGBT open switch fault applied to 3-phase AC/DC PWM converter," Journal of Power Electronics, Vol. 12, No.1, pp.120-127, Jan. 2012.

[9] S. Khomfoi, W. Sae-Kok, and I. Ngamroo,"An open circuit fault diagnostic technique in IGBTs for AC to DC converters applied in microgrid applications," Journal of Power Electronics, Vol. 11, No. 6, pp.801-810, Nov. 2011.

[10] R. L. A. Ribeiro, C. B. Jacobina and E. R. C. da Silva, "Fault-tolerant voltage-fed pwm inverter AC Motor drive systems," IEEE Trans. Ind. Applicat., Vol. 51, No. 2, pp. 439-446, Apr. 2004.

[11] B.-G. Park, K.-J. Lee, R.-Y. Kim, and D.-S. Hyun, "Low-cost fault diagnosis algorithm for switch open-damage in BLDC motor drives," Journal of Power Electronics, Vol. 10, No. 6, pp.702-708, Nov. 2010.

[12] M. Awadallah and M. Morcos, "Automatic diagnosis and location of open-switch fault in brushless DC motor drives using wavelets and neuro-fuzzy systems," IEEE Trans. Energy Convers., Vol. 21, No. 1, pp.104-111, Mar. 2006.

[13] F. Charfi, F. Sellami, and K. Al-Haddad,"Fault diagnosis in power system using wavelet transforms and neural networks," in Proc. IEEE Int. Symp. Ind. Electron., pp. 1143-1148, 2006.

[14] S. Morimoto, M. Sanada, and Y. Takeda, "Mechanical sensorless drives of IPMSM with online parameter identification," IEEE Trans. Ind. Applicat., Vol. 42, No. 5, pp. 1241-1248, Sep./Oct. 2006.

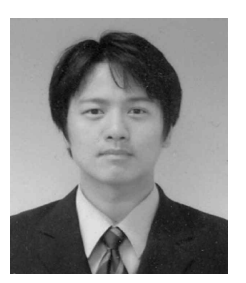

Byoung-Gun Park received his B.S. in Electrical Engineering from Myongji University, Yongin, Korea, in 2005, and his M.S. and Ph.D. in Electrical Engineering from Hanyang University, Seoul, Korea, in 2007 and 2011, respectively. Since 2011, he has been with the Korea Electrotechnology Research Institute (KERI), Changwon, Korea, where he is currently a Senior Researcher in the Electric Motor Research Center. His current research interests include motor drives, fault tolerant control, and power converter systems for electric vehicles. Dr. Park is a member of the IEEE Power Electronics, Industrial Electronics, and Industry Applications Societies. He is also a member of the Korean Institute of Power Electronics and the Korean Institute of Electrical Engineers.

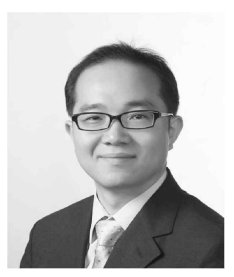

Rae-Young Kim received the B.S. and M.S. degrees from Hanyang University, Seoul, Korea, in 1997 and 1999, respectively, and the $\mathrm{Ph} . \mathrm{D}$. degree from Virginia Polytechnic Institute and State University, Blacksburg, VA, USA, in 2009, all in electrical engineering.

From 1999 to 2004, he was a Senior Researcher at the Hyosung Heavy Industry R\&D Center, Seoul, Korea. In 2009, he was a Postdoctoral Researcher at National Semiconductor Corporation, involved in a smart home energy management system. Since 2010, he has been with Hanyang University, where he is currently an Assistant Professor in the Department of Electrical and Biomedical Engineering. His research interests include modeling and control of power converter systems, soft-switching techniques, energy management systems in smart grid applications, power converter systems for renewable energies, and motor drive systems. Dr. Kim has been a Member of the IEEE IAS Industrial Power Converter Committee since 2009 and also served as an Associated Editor for the JOURNAL OF POWER ELECTRONICS and the JOURNAL OF ELECTRICAL ENGINEERING \& TECHNOLOGY. He was a recipient of the 2007 First Prize Paper Award from the IEEE IAS.

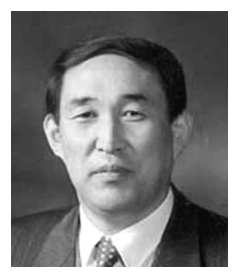

Dong-Seok Hyun received his B.S. and M.S. in Electrical Engineering from Hanyang University, Seoul, Korea, in 1973 and 1978, respectively, and his Ph.D. in Electrical Engineering from Seoul National University, Seoul, Korea, in 1986. From 1976 to 1979, he was with the Agency of Defense Development, Korea, as a Researcher. He was a Research Associate in the Department of Electrical Engineering, University of Toledo, Toledo, OH, from 1984 to 1985, and a Visiting Professor in the Department of Electrical Engineering, Technical University of Munich, Munich, Germany, from 1988 to 1989. Since 1979, he has been with Hanyang University, where he is currently a Professor in the Department of Electrical Engineering and the Director of the Advanced Institute of Electrical Engineering and Electronics (AIEE). He is the author of more than 650 publications concerning electric machine designs, high-power engineering, power electronics, and motor drives. His current research interests include power electronics, motor drives, traction, and their control systems. Dr. Hyun is a member of the IEEE Power Electronics, Industrial Electronics, Industry Applications, and Electron Devices Societies. He is also a member of the Institution of Engineering and Technology (IET), the Korean Institute of Power Electronics, and the Korean Institute of Electrical Engineers. 